\title{
A Review of Cognitive and Behavioral Interventions for Tic Disorder
}

\author{
Kyoung Min Kim ${ }^{1,2}$, Eunju Bae ${ }^{3}$, Jiryun Lee ${ }^{2}$, Tae-Won Park ${ }^{4}$, and Myung Ho Lim \\ ${ }^{1}$ Department of Psychiatry, College of Medicine, Dankook University, Cheonan, Korea \\ 2Department of Psychiatry, Dankook University Hospital, Cheonan, Korea \\ ${ }^{3}$ Graduate School of Psychology, Dankook University, Cheonan, Korea \\ ${ }^{4}$ Department of Psychiatry, Jeonbuk National University Hospital, Jeonju, Korea \\ ${ }^{5}$ Department of Psychology, College of Health Science, Dankook University, Cheonan, Korea
}

Objectives: Tic disorder is a neurodevelopmental disorder characterized by multiple involuntary movements of muscles or vocalization. Although tic symptoms subside as the patient ages, some patients suffer from significant functional impairments related to severe tic symptoms. This manuscript aimed to review the latest scientific evidences for the effect of cognitive-behavioral interventions on tic disorder.

Methods: The relevant studies were identified by searching medical research databases. We focused our search on studies published between 2000 and 2020 in order to reflect the latest scientific evidence. A total of 821 articles were identified in the initial database search and 27 articles were finally included for the review after the exclusion of duplicated and irrelevant articles.

Results: Behavioral therapies including habit reversal training, Comprehensive Behavioral Intervention for Tics, and exposure and response prevention were the most widely studied interventions for tic disorder and are recommended as first-line treatments for tic disorders with high confidence. Cognitive psychophysiologic approaches were also reported to be effective.

Conclusion: Further studies are needed to support the future treatment of tics with low-cost and more widely available treatments, in order to ensure better treatment outcomes.

Key Words: Tourette syndrome; Tic disorders; Cognitive behavioral therapy.

Received: October 19, 2020 / Revision: December 15, 2020 / Accepted: December 31, 2020

Address for correspondence: Myung Ho Lim, Department of Psychology, College of Health Science, Dankook University, 119 Dandae-ro, Dongnam-gu, Cheonan 31116, Korea

Tel: +82-41-550-3263, Fax: +82-41-550-3007, E-mail: paperose@dankook.ac.kr

\section{INTRODUCTION}

Tic disorder is neurodevelopmental movement disorder characterized by the symptoms of sudden, rapid, recurrent, nonrhythmic motor movements, and vocalizations [1]. Tic disorders consists of four diagnostic categories: provisional tic disorder, persistent (chronic) motor or vocal tic disorder, Tourette's disorder, and other specified and unspecified tic disorders [1]. Tourette's disorder is a severe form of tic disorder, which is defined by the presence of both multiple motor and one or more vocal tics for more than one year since the first onset of tic symptoms [1].

Tic disorder is associated with heterogeneous symptoms at presentation both across and within individuals, including simple and complex, motor or vocal tics [2]. Simple motor tics often involve brief, repetitive movements such as eye blink-

This is an Open Access article distributed under the terms of the Creative Commons Attribution Non-Commercial License (https://creativecommons.org/licenses/by-nc/4.0) which permits unrestricted non-commercial use, distribution, and reproduction in any medium, provided the original work is properly cited. ing, grimacing, head jerks, and shrugging; simple vocal tics include sniffing, throat clearing, grunting, and coughing [3,4]. Some patients often suffer from complex tics involving larger muscle groups (i.e., arm thrusts, gyrating, and bending), and vocalizations such as words, short phrases, or even echolalia (repeating the words of others), palilalia (repeating oneself), or coprolalia (saying obscene words) [3-5]. Although motor tics and vocal tics are differentiated, vocal tics are the result of contractions of laryngeal, respiratory, oral, or nasal muscles [6]. Tic symptoms have the characteristic of progression in a rostral-caudal fashion; they also wax and wane in severity, and the symptoms can change over time [5].

Tic symptoms usually start around the age of 6 years to 8 years and are common in schoolchildren, where they affect 15-25\% [5]. However, tic symptoms are transient in most cases and drastically reduce in the period of adolescence $[1,5]$. A meta-analysis reported a wide prevalence rate of transient tic disorder from $0.40 \%$ to $18.26 \%$, with an average rate of $2.99 \%$ [95\% confidence interval (CI): 1.60 to 5.61]; to contrast, 
the prevalence of Tourette's disorder was reported as $0.77 \%$ ( $95 \%$ CI: $0.39 \%$ to $1.51 \%$ ) [7]. Tic disorder affects males more commonly than females, with a male-to-female ratio of between 2:1 and 4:1 [1]. The prevalence of Tourette's syndrome in boys has been reported as $1.06 \%$, compared to $0.25 \%$ in girls [7]. Tic disorders are less common in adulthood, with the reported prevalence of Tourette's syndrome being $0.05 \%$. Whereas tic symptoms are known to be exacerbated by emotional stress, anxiety, fatigue, and watching television, they often attenuate during relaxation, concentration, and physical exercise [8].

Dysfunction in the basal ganglia and related cortico-striato-thalamo-cortical circuits are involved in the generation of tics [9]. In addition, dysfunction of the dopaminergic system and GABAergic inhibition have been implicated as the central pathophysiology of tics $[9,10]$. With regard to the prognosis of tic disorders, Hassan and Cavanna [11] reviewed the scientific literature published between 1990 and 2010, and reported the predictors of increased tic severity in adulthood to include higher childhood tic severity, smaller caudate volume, and worse fine motor control; in addition, the presence of untreated comorbid psychiatric disorders such as attentiondeficit/hyperactivity disorder and obsessive and compulsive disorder were reported to adversely affect the long-term outcome of Tourette's disorder [11].

European clinical guidelines for Tourette's disorder and other tic disorders recommend psychoeducation and monitoring when the patient has no indication for treatment [12]. However, if the patient has indications for treatment such as subjective discomfort (e.g., pain or injury), sustained social problems (e.g., social isolation or bullying), emotional problems (e.g., reactive depressive symptoms), or functional interference (e.g., impairment of academic achievements), the treatment options of symptom-focused behavioral therapy [e.g., habit reversal training (HRT) or exposure and response prevention (ERP) therapy] or pharmacological therapy should be considered [12]. For pharmacological treatment, antipsychotics such as risperidone, aripiprazole, sulpride, haloperidol, and pimozide, which are dopamine-lowering agents, are the main treatment options recommended [12]. Alpha-adrenergic agonists such as clonidine and guanfacine were also reported to have efficacy in reducing tic severity. The third treatment option includes non-pharmacologic biological therapy such as deep brain stimulation or transcranial magnetic stimulation [13].

Pharmacological treatment usually has a fast onset in terms of treatment effect compared to behavioral treatment options. However, due to the risk of general side effects associated with pharmacotherapy such as sedation, weight gain, hyperprolactinemia, and extrapyramidal symptoms, as well as limited evidence for the effect of pharmacotherapy on alleviating tic symptoms, clinicians should consider recommending behavioral therapy before pharmacological treatment if patient preferences and the availability of therapists for behavioral therapy allow this $[12,14,15]$. A comprehensive systematic review [4] reported high confidence in the Comprehensive Behavioral Intervention for Tics (CBIT) reducing tics relative to psychoeducation and supportive therapy, whereas moderate or low confidence were reported in relation to pharmacologic treatments being likely to reduce tics more than placebo.

Considering the possible efficacy and harm associated with behavioral and pharmacological treatments, an update on the latest scientific evidence for the efficacy of cognitive-behavioral interventions for tic disorder is important in order for patients and clinicians to formulate proper treatment strategies. However, previous guidelines for tic disorder were reported in 2011 and 2012, almost a decade ago [13,16-19]. Moreover, there is a lack of studies on behavioral interventions for tic disorder in South Korea, despite a few reports of reviews and case-studies evaluating cognitive-behavioral interventions for tic disorders [20,21]. Thus, this study aimed to review the latest scientific evidence for the effect of cognitive-behavioral interventions on tic disorders, and discuss the future study directions.

\section{METHODS}

Relevant studies were identified by searching medical research databases including Web of Science, PubMed, MEDLINE, and PSYCInfo in July 2020 and August 2020. Search terms used included 'tic' or 'Tourette' AND 'cognitive therapy, 'behavior therapy,' or 'habit reversal.' We focused our search on manuscripts published between 2000 and 2020, in order to reflect the latest scientific evidence. In total, 821 articles were identified in the initial database search; 292 duplicated articles were excluded. After the exclusion of articles with irrelevant topics and small case numbers, 27 articles were finally included for the review. The search process was presented in the Fig. 1.

\section{RESULTS}

\section{Overview: history of treatment modality for tics}

The original behavioral model of tic disorder was introduced by Azrin and Nunn [22], which was based on the idea that tics resemble habits, and was later modified by Turpin [23]. Fründt et al. [24] reviewed the behavioral therapies for tic disorder and categorized them into past, present, and future treatment modalities. Past treatments included psychoanalytic and supportive psychotherapy (SP) as well as massed practice (MP), whereas HRT, CBIT, and ERP were considered present treat- 


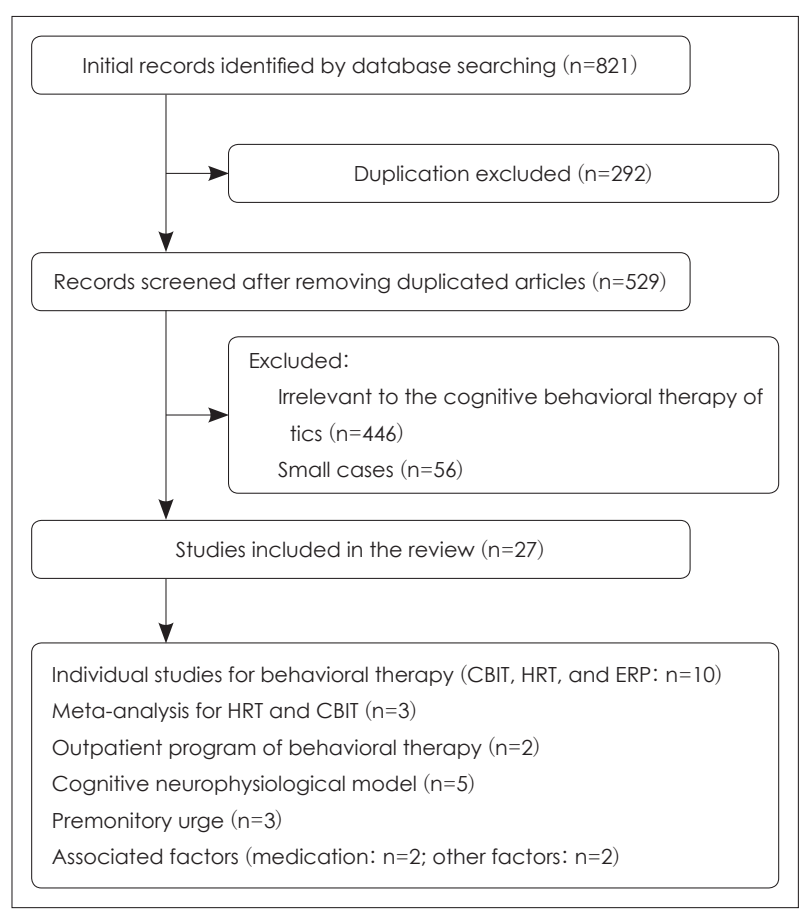

Fig. 1. The flow diagram for the inclusion and exclusion of studies. CBIT: Comprehensive Behavioral Intervention for Tics, HRT: habit reversal training, ERP: exposure and response prevention.

ments. Finally, internet-based training, telehealth approaches, autonomic modulation, and neuro-feedback are being studied as potential future treatments, although there is insufficient evidence to make clear recommendations regarding their utility at present.

\section{Assessment}

The most widely used tools to assess tic severity in clinical trials are the Yale Global Tic Severity Scale (YGTSS), Clinical Global Impression Severity (CGI-S) and Improvement (CGI-I) Scales. The YGTSS is a clinician-rated, semi-structured interview consisting of 10 items that was developed by Leckman et al. [25]. The YGTSS includes an assessment of the number, frequency, intensity, complexity, and interference from motor and vocal tics, as well as overall impairment. It is useful to assess tic severity in children and adolescents as well as adults. The CGI comprises of two companion one-item measures evaluating the severity of psychopathology (CGI-S) and change from the initiation of treatment (CGI-I) on a 7-point scale [26], and was developed for use in National Institute of Mental Health-sponsored clinical trials. CGI provides a brief, stand-alone assessment of the patient's global functioning for the clinician [27]. Apart from these two tools, the Tourette's Syndrome Severity Scale [28], Tourette's Disorder Scale-Clinician Rated [29], Hopkins Motor and Vocal Tic Scale [30], Tourette's Syndrome Questionnaire [31], Child Tourette Syndrome Impairment Scale [32], and Videotape Ratings and
Tic Counts [33] can also be used to evaluate tic symptoms.

\section{Psychotherapy and MP}

Past treatment options for tic disorders include psychoanalytic and SP as well as MP [24]. Psychoanalytic psychotherapy has failed to prove its efficacy for reducing tic symptoms, and SP also yielded negative results with regard to tic symptoms. However, SP and psychoeducation are included in guidelines for tic management [16] due to the efficacy of SP in improving overall wellbeing and psychosocial functioning, despite no clear effect on tic reduction.

MP is based on the concept that tics are learned maladaptive habits that can be replaced by other flexible and adaptive behaviors [34]. It involves training for accurate, effortful, repetitive, rapid, and voluntary production of the individual's tics over a certain amount of time (15-30 minutes) until the tics decrease [35]. Despite some case reports and studies supporting its efficacy, MP has been shown to be inferior to modern behavioral interventions for tic symptoms, and there is no current evidence supporting its utility $[24,36]$.

\section{HRT and CBIT}

Currently, the mainstream treatment modalities for tic disorder include HRT and CBIT [24,37]. HRT consists of nine different techniques within four domains: 1) Awareness training, in order to help patients detect the situations and signs related to tic symptoms; 2) competing response training, instructing individuals to perform incompatible movements against the tic using antagonistic muscles; 3) motivation, focusing on the social and environmental consequences of tics; and 4) generalization, which is a complete rehearsal of the HRT in life $[24,38,39]$. CBIT is an extended treatment program of HRT and includes the HRT techniques as core components. In addition to the HRT techniques, CBIT also includes psychoeducation, relaxation training, behavioral rewards, and function-based interventions [24,37]. The functional intervention identifies situational antecedents and the consequences of tic severity, and develops individualized strategies to reduce these factors [40].

\section{Individual studies evaluating the efficacy of HRT and CBIT}

Tables 1 and 2 show individual randomized controlled trials evaluating behavioral interventions for tic or Tourette's disorders. Deckersbach et al. [38] compared the effect of HRT and SP in a randomized controlled trial. The study was performed by delivering 14 sessions of each therapy in 30 adults with Tourette's disorder (15 patients for HRT versus 15 patients for SP). Tic severity between pre- and post-treatment reduced significantly in the HRT group but not the SP group. 


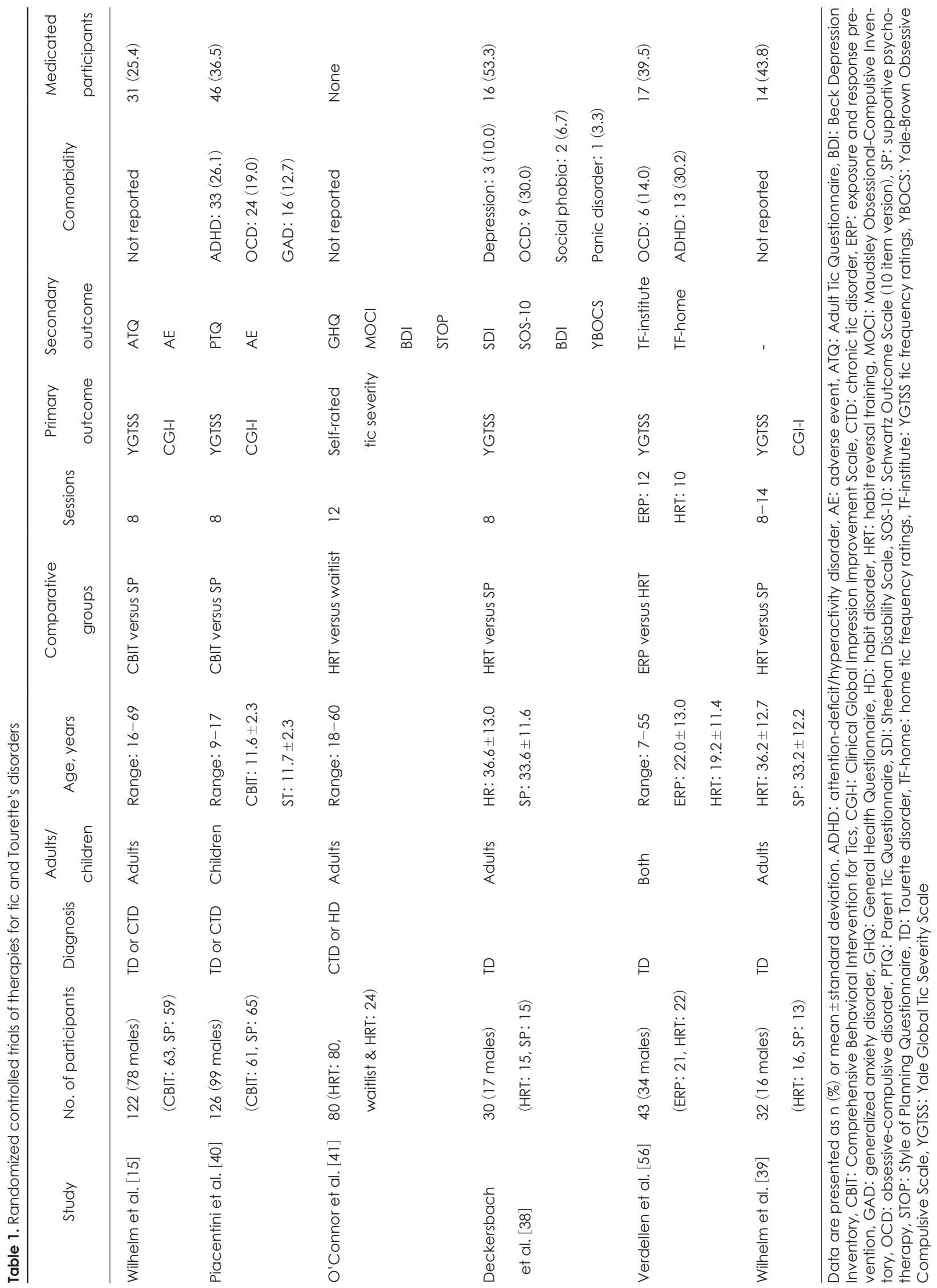




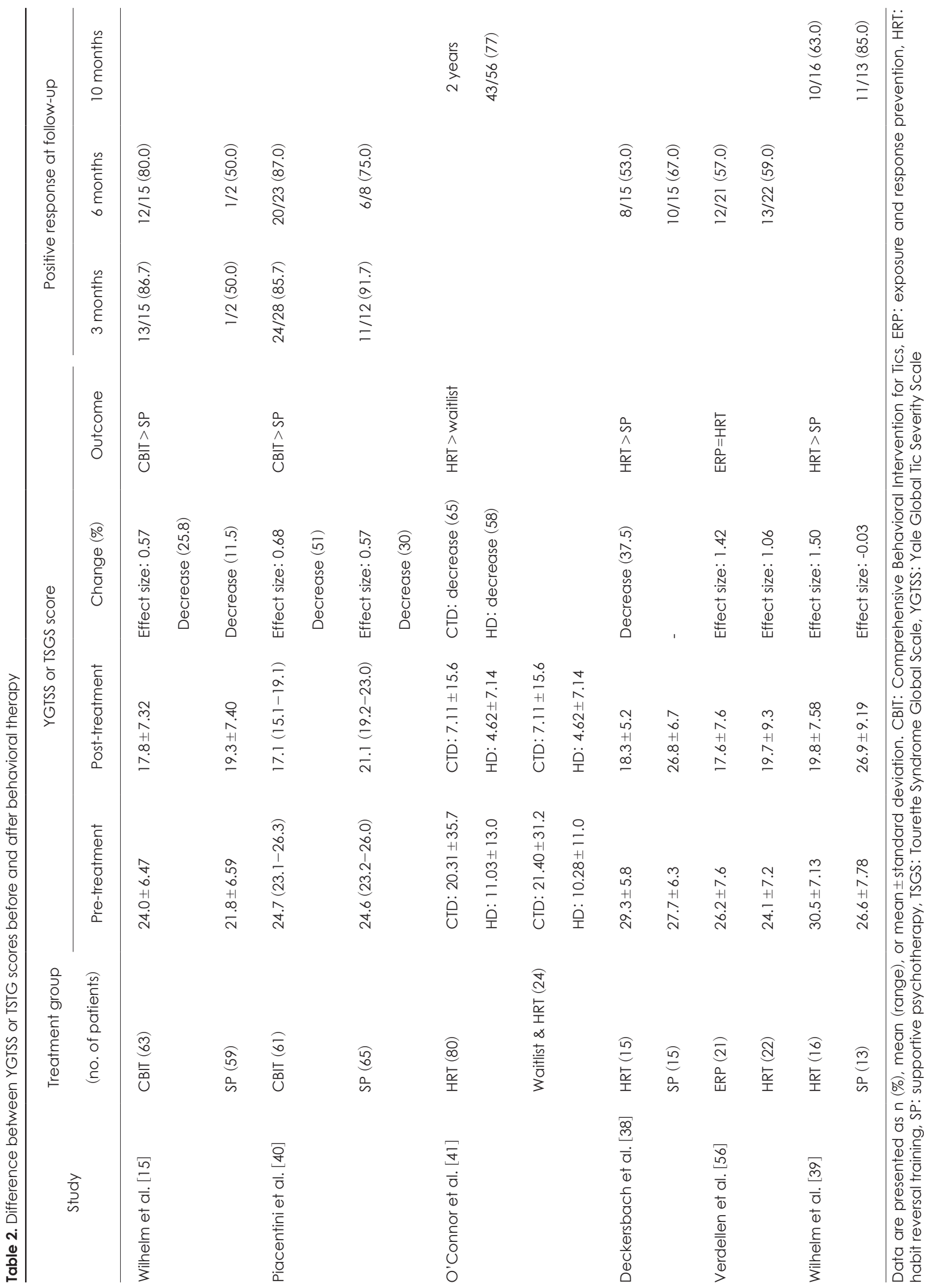


In addition, 10 of the 15 participants in the HRT group were classified as much or very much improved at the end of treatment, compared to two out of 15 subjects in the SP group. In addition, the reduction of tic severity observed after treatment remained stable at the 6-month follow-up only in the HRT group, although both groups demonstrated improvements in life-satisfaction and psychosocial functioning.

Another randomized controlled study by Wilhelm et al. [39] compared the effects of HRT and SP. Twenty-nine patients with Tourette's disorder were randomly assigned to 14 sessions of either HRT group $(n=16)$ or SP group $(n=13)$. Tic severity reduced significantly over the course of treatment in the HRT group $(t=8.29, \mathrm{p}<0.01)$ but not in the SP group $(\mathrm{t}=-0.14, \mathrm{p}=0.89)$. The HRT group also reported significantly lower functional impairment at post-treatment (mean score $=9.44$ ) than the SP group (mean score $=22.69 ; \mathrm{t}=3.15, \mathrm{p}<0.01$ ). In addition, after 10 months, the HRT group remained significantly improved in terms of tic severity and functional impairment, whereas the SP group remained at their pretreatment levels.

O'Connor et al. [41] also investigated the efficacy of a fourmonth cognitive-behavioral program based on HRT for treatment of tic disorder $(n=47)$ and habit disorder $(n=43)$. Among the participants, thirty-eight were assigned to a waitlist control group who subsequently received treatment. Although there were no significant differences in tic and habit severity between the baseline and waitlist period, participants showed a significant decrease in tic and habit frequency $(\mathrm{F}=$ 11.85; $\mathrm{p}<0.001)$ and tic and habit intensity $(\mathrm{F}=70.57 ; \mathrm{p}<0.001)$ following treatment, and the decrease was maintained at twomonth follow-up.

The efficacy of CBIT on tics was also investigated in a neuroimaging study by Deckersbach et al. [42], who examined the change of activity in brain regions using functional MRI. A significant decrease in striatal (putamen) activation between pre- and post-treatment was observed. In addition, changes in task-related activation of Brodmann's area 47 (inferior frontal gyrus) were negatively correlated with changes in tic severity, which suggests that CBIT might promote the normalization of aberrant cortico-striato-thalamo-cortical circuits in patients with Tourette's disorder.

\section{Two large controlled studies investigating the efficacy of HRT and CBIT}

Wilhelm et al. [15] tested the efficacy of a CBIT in a large sample of adults $(n=122)$ with Tourette's disorder. Participants received eight sessions of CBIT or supportive treatment for 10 weeks. Tic severity decreased significantly more in the CBIT group (YGTSS score $=24.0$ to 17.8 from baseline to end-point) compared to the controls [YGTSS score $=21.8$ to $19.3 ; \mathrm{p}<0.001$; effect size $(\mathrm{ES})=0.57$ ]. Moreover, 24 of 63 patients were rated as much or very much improved on the CGI-I Scale compared to 4 of 63 controls.

Piacentini et al. [40] investigated the efficacy of a CBIT in children and adolescents. A large sample of patients $(n=126)$ were enrolled and randomly assigned to 8 sessions over 10 weeks of CBIT $(n=61)$ or a control treatment (supportive therapy and education; $n=65)$. CBIT resulted in a significantly greater decrease on the YGTSS score (24.7 to 17.1) from baseline to end-point compared to controls (24.6 to $21.1 ; \mathrm{p}<0.001 ; \mathrm{ES}=0.68)$. In addition, significantly more children in the CBIT group were rated as much or very much improved on the CGI-I Scale than controls (52.5\% vs. $18.5 \%$, respectively; $\mathrm{p}<0.001)$.

\section{Studies evaluating the efficacy of CBIT in specific populations or settings}

Other studies have evaluated the efficacy of CBIT in specific populations such as children and specific settings including outpatient or videoconference. Bennett et al. [43] evaluated the efficacy of a CBIT in 15 children aged between 5 and 8 years with six sessions of intervention over 8 weeks. The tic severity of participants reduced significantly after treatment (mean=14.5; ES=0.73) and at 3-month follow-up (mean=13.7; $\mathrm{ES}=1.00)$ relative to baseline (mean=22.7). Rowe et al. [44] also examined the efficacy of a CBIT in 30 children with tic disorder and observed a significant reduction in tic severity (mean score; from 4.63 at baseline to 1.1 at post-treatment, $\mathrm{p}<0.0001$ ).

Although CBIT has shown its efficacy in reducing the severity of tic symptoms, some disadvantages such as the longterm sessions lasting 10 weeks, regular visits to the hospital, and unavailability of expert therapists act as barriers for patients to receive CBIT [37]. In order to overcome these inconveniences raised from the standard CBIT protocol consisting of 8 sessions over 10 weeks, Blount et al. [45] examined the treatment outcome in 5 individuals with Tourette's disorder using an intensive outpatient program compressed into one week. Four out of 5 participants reported a significant reduction in tic severity, with an average decrease of 11.5 points in the YGTSS. Himle et al. [46] compared the efficacy of videoconference versus face-to-face delivery of CBIT and reported that both treatment delivery modalities led to significant decreases in tic symptoms, with no between-group differences.

\section{Meta-analyses and systematic reviews evaluating the efficacy of HRT and CBIT}

A meta-analysis investigated randomized controlled trials (RCTs) to test the efficacy of HRT and CBIT for tic disorders. A total of 8 RCTs published between 1990 and 2012, with a total sample of 438 participants, were included in the metaanalysis. Participants receiving HRT or CBIT were more like- 
ly to exhibit a treatment response compared to control interventions, with an odds ratio of 5.77 (95\% CI: 3.23, 10.30), and treatment response on the CGI-I Scale identified a number needed to treat of three [47].

Bate et al. [48] also conducted a meta-analysis of the efficacy of HRT on reducing symptoms of maladaptive repetitive behaviors, including stuttering, tics, nail biting, temporomandibular disorder, thumb sucking, and mixed repetitive oral-digital habits. A total of 575 participants in 18 studies published between 1980 and 2007 were included, and a large ES between pre- and post-treatment assessments with HRT ( $d=0.80)$ was observed compared to control conditions. Wille and Pringsheim [49] performed a meta-analysis with four high-quality clinical trials of HRT $(n=2)$ and CBIT $(n=2)$ for tics. They reported the mean differences of YGTSS scores to improve after each treatment compared to SP, favoring HRT (mean difference $=3.66$; 95\% CI: 2.25 to 5.07 ) and CBIT (mean difference $=10.52$; 95\% CI: 7.44 to 13.59 ).

In addition to these meta-analyses, multiple systematic reviews evaluating treatment modalities for tics have reported the most promising outcomes on reducing tic symptoms to be associated with the behavior therapies HRT and CBIT [24,50-53].

\section{ERP}

ERP was originally developed to treat obsessive-compulsive disorder (OCD) by Meyer [54] and has proved its efficacy in the treatment of OCD. Theoretically, ERP includes techniques of exposure to the sensations and urges that precede tics, and response prevention of the tics to target the habituation of the patient to the premonitory urges of tics, resulting in tic reduction [55]. In the ERP training, patients are required to endure the premonitory urges for a long time of period (up to 2 hours), with resistance against tic execution sessions [55]. Whereas HRT focuses on a limited number of tics at once, ERP targets the premonitory urges of multiple tics simultaneously [56].

In an early case report of a patient with Tourette's disorder, ERP was applied for the premonitory urge and tic movements, and an improvement in tic symptoms and relief of the premonitory itching sensations were observed [57]. Another case report of an 11-year-old boy demonstrating three repetitive behaviors found the frequency of the repetitive behaviors to be relieved by the ERP [58]. Verdellen et al. [56] compared the effect of ERP ( $n=21)$ versus HRT $(n=22)$ in 43 Tourette's disorder patients. The participants were given 12 weekly treatment sessions of each treatment modality. Tic symptom severity improved in both treatment conditions and no significant differences were found between the treatment conditions, which indicated that tic symptoms can be treated effectively by both treatments. A recent study by Nissen et al. [59] tested the combined form of HRT and ERP and reported that two-thirds of participants responded to the treatment. Finally, previous review articles have suggested ERP as 'probably efficacious treatment' and the first line behavioral intervention together with HRT $[60,61]$.

\section{Cognitive behavioral models}

Individuals with a tic disorder often suffer from cognitive distortion including anticipation, rigid beliefs, a judgmental style of thinking, attentional focus, and a perfectionistic style of planning action as well as tic symptoms [62-64]. Despite the effectiveness of behavioral therapies such as HRT and ERP, which address the tic symptoms in isolation, cognitive distortion should be also considered to improve the treatment outcome. Cognitive psychophysiological intervention focuses more on the cognitive change of the background activity in which the tic occurs [65]. This approach is based on a cognitive model that includes modules of motivation, developing awareness, identifying at risk context, reducing tension, increasing flexibility, addressing styles of planning action, discriminating cognitive confusion, emotional regulation, and maintaining the gains [66]. This approach was reported to have had strong ES on improving the severity of tic symptoms per se in adults as well as the perfectionism and self-esteem of patients at 6-month follow-up [65]. Another study of the cognitive behavioral approach also demonstrated its efficacy for improving general behavioral problems in addition to tic symptoms in children [62].

Some studies reported the usefulness of individual techniques such as contingency management, function-based interventions, relaxation training [67], self-monitoring [67], mindfulness-based stress reduction [68], and tension reduction [69]. However, most of these techniques are included as a part of modules in the comprehensive cognitive model. Thus, further studies on integrative cognitive model would be needed rather than on the independent usefulness of the individual techniques.

\section{Tics, premonitory urge, and neurophysiologic process}

In addition to cognitive distortion, patients with tics are reported to present impairment in several neurophysiologic processes such as learning, verbal fluency, fine motor coordination, inhibitory control, and premonitory urges, which might be caused by the basal ganglia dysfunction or high levels of sensorimotor activation [70]. Studies for these neurophysiologic mechanisms performed the experimental work to investigate the physiologic mechanisms associated with tics. Premonitory urges are often thought to be a core mechanism of inducing tic symptoms. Thus, it becomes a treatment tar- 
get of habituation based on the theoretical model or ERP. Two studies investigated whether there is a rebound effect of tics after tic suppression for a period of ERP and reported that voluntary suppression of tics does not induce a rebound of tics that exceeds the average rate of previous tic severity $[71,72]$. Verdellen et al. [73] also tested the hypothesis that habituation to the unpleasant premonitory urge of the tic is an underlying mechanism of change in ERP, and the results supported their hypothesis. However, a large study including 126 adults and 122 children by Houghton et al. [74] tested whether premonitory urges decrease in youth with tic disorder with the use of behavior therapy versus psychotherapy. Although the premonitory urges in adults (but not in children) who responded to behavior therapy significantly decreased across treatment, results failed to find a specific effect of behavior therapy on reducing premonitory urge severity, which casts doubt on the hypothesis that habituation is a core process underlying the effectiveness of behavior therapy on tics. Nam et al. [75] also reported that it is still unknown whether the severity of a premonitory urge is directly related to the severity of the subsequent tic symptoms, and the effects of pharmacological treatments on premonitory urges have also been inconsistent.

O'Connor et al. [76] compared the performance on executive function and a range of skilled motor tests in people with tic disorders and controls and examined the effect of cognitive behavior therapy (CBT) on motor performance. They reported that the motor performances are significantly different between tic disorders and controls. Also, the CBT selectively improved motor performance in patients with tics and this improvement was related to clinical outcome measures. Morand-Beaulieu et al. [77] assessed the event-related potentials as predictors of CBT outcomes in patients with tic disorder. They found that CBT can normalize motor processes related to stimulus-response compatibility in Tourette's disorder patients and ERP can predict the amount of tic symptoms improvement induced by the CBT. Lavoie et al. [70] also found that patients with Tourette's disorder presented with reduced cortical activation that was associated with response inhibition; this was restored by CBT.

\section{Associated variables affecting on treatment outcomes of behavioral treatment}

\section{Tic medication}

O'Connor et al. [78] administered CBT to people diagnosed with either Tourette's disorder or chronic tic disorder. The sample was divided into medicated $(\mathrm{n}=23)$ and non-medicated groups $(n=53)$. They found significant improvement of tics after CBT in both groups and no significant differences in the improvement of tics between medicated and non-medicated groups. Sukhodolsky et al. [79] also examined the moderating effect of medication in response to CBIT in children and adults with Tourette's syndrome and chronic tic disorders. They reported that participants showed tic reduction after CBIT regardless of tic medication use, but only participants receiving medication showed a reduction of tics in SP (control group). The findings of these studies indicate that CBT is an effective treatment for tics either in combination with medication or alone.

\section{Other factors}

Sukhodolsky et al. [79] also reported that age, sex, family functioning, tic characteristics, treatment expectancy, and comorbid psychiatric disorders such as attention-deficit/hyperactivity disorder, OCD, and anxiety disorders do not moderate the effect of CBIT on tics. Specht et al. [80] investigated correlates of the ability to suppress tics in 12 youths aged 10 years to 17 years with moderate-to-marked chronic tic disorders in a reinforced tic suppression test. They found that general cognitive function (intelligence) might be associated with the ability to suppress tics, whereas age, attention, tic severity, and severity of premonitory urge were not. Although these previous studies by Sukhodolsky et al. [79] and Specht et al. [80] reported that age is not a moderating factor for suppressing tic symptoms, the prevalence and severity of tic disorders is well known to decrease throughout the adolescence period $[1,5,81]$, which is thought to be associated with brain development from early childhood through the mid-20s $[82,83]$. Thus, future studies considering the effect of age or brain development on the efficacy of behavioral therapy on tics are needed.

Bloch and Leckman [84] reviewed the long-term prognosis of Tourette's disorder and reported that comorbid psychiatric conditions such as OCD and other anxiety and depressive disorders are common during adolescence. They also reported that enhancing self-esteem by encouraging strong friendships and exploration of interests is crucial to positive outcomes in adulthood among patients with Tourette's disorder.

\section{DISCUSSION}

The present study reviewed the latest evidence for the use of cognitive and behavioral interventions in the treatment of tic disorders. The HRT and CBIT were the most widely studied interventions and recommended as first-line treatments for tic disorders with high confidence $[4,16,18,85]$. Awareness training and competing response training are the core components of HRT and CBIT. In awareness training, clinicians help the patient to define and identify early tic signals such as premonitory urges and early tic movements. Once the tics are defined, patients practice recognizing tic occurrences in 
sessions in order to enhance their awareness [37]. After awareness training, the clinician and the patient develop an alternative behavior using the antagonistic muscle which is physically incompatible with the tics (called a competing response). The behaviors are practiced for approximately 1 min or until the premonitory urge subsides. In addition to these two core components, HRT and CBIT include various components used in cognitive behavioral interventions to enhance the treatment outcome, such as psychoeducation, self-monitoring, relaxation training, function-based intervention, behavioral rewards, and relapse prevention. These components are somewhat selectively included by the individual treatment protocols. ERP, targeting the habituation of premonitory urges, is another treatment option for tics, which has been recommended as a first line behavioral intervention although studies on its use are fewer than for HRT and CBIT [61].

The efficacy of these behavioral interventions was not affected by factors such as tic medication use, age, sex, family functioning, tic characteristics, and psychiatric comorbidities. On the other hand, positive social supports such as encouraging strong friendships and exploration of interests are important factors for good prognosis in patients with tic disorders. In addition, SP was also effective in improving psychosocial well-being, although it was not effective in reducing the severity of tic symptoms.

\section{Future directions}

Fründt et al. [24] suggested future treatments for tics, such as internet-based training, telehealth approaches, autonomic modulation, and neuro-feedback, although there is no evidence regarding their efficacy yet. Any single treatment modality among the various pharmacotherapy and behavioral interventions is insufficient to induce the complete remission of all tic cases, despite their individual efficacies. Thus, studies developing other treatment modalities to enhance treatment outcomes for patients suffering from tics are needed.

Notably, despite their efficacy and utility, traditional faceto-face behavioral interventions have some barriers such as high cost, the shortage of counseling professionals, and restricted implementation of intensive therapies [37,86]. Due to the recent advancements in information technology, internetbased electronic devices are being actively adopted in the assessment and treatment of psychiatric disorders [86]. For example, virtual-reality (VR), which is a computer-generated simulation of a three-dimensional environment in which one can interact in a seemingly real way [87], is being implemented and proving its benefits in multiple psychiatric disorders such as anxiety disorder, post-traumatic disorder, and psychosis; it is also showing benefits in pediatric psychiatry for attention-deficit/hyperactivity disorder and autism spectrum disorder [87,88]. Most VR-related interventions are based on the cognitive-behavioral approach, such as VR-exposure therapy [89]. In addition, VR therapy can provide a realistic environment based on an individual's needs, with repetitive, consistent, and systematic training. VR therapy help patients to overcome the barriers induced by face-to-face behavioral interventions such as high costs and the lack of professional therapists. However, studies adopting the VR-technique for treating tic disorder are lacking, compared to its wide use in other psychiatric disorders, warranting future studies evaluating the VR-technique.

Although pharmacological treatment has showed no stronger efficacy than behavioral therapies [4], it is still important to consider the combination therapies of pharmacological and behavioral therapies, because any single treatment option cannot completely relieve the pain the patients with severe tic symptoms. Moreover, new agents such as the D-cycloserine have presented promising outcomes when augmenting behavior therapy to enhance the treatment of tics. Thus, further studies adopting the combination of behavioral and pharmacological therapies including newly introduced medicine [90].

\section{CONCLUSION}

The present study reviewed the latest scientific evidence for the effect of cognitive-behavioral interventions on tic disorders. The cognitive-behavioral therapies including HRT, CBIT, and ERP are the effective and recommended as the firstline treatment options to improve the tic symptoms. However, their efficacies are not sufficient to relieve all the tic symptoms completely. Thus, future studies including newer techniques are needed to improve the treatment outcomes for the patients being suffered from the tics.

\section{Acknowledgments}

This research was funded by the Institute for Information \& communication Technology Planning \& evaluation (IITP), Ministry of Science and ICT, Republic of Korea (ID: 2020-0-00506).

\section{Conflicts of Interest}

The authors have no potential conflicts of interest to disclose.

\section{Author Contributions}

Conceptualization: Kyoung Min Kim, Tae-Won Park, Myung Ho Lim. Data curation: Kyoung Min Kim, Eunju Bae, Jiryun Lee. Formal analysis: Kyoung Min Kim, Eunju Bae, Jiryun Lee. Funding acquisition: Kyoung Min Kim. Investigation: Eunju Bae, Jiryun Lee, Myung Ho Lim. Methodology: Tae-Won Park, Myung Ho Lim. Project administration: Kyoung Min Kim, Tae-Won Park, Myung Ho Lim. Resources: Kyoung Min Kim, Myung Ho Lim. Software: Kyoung Min Kim, Myung Ho Lim. Supervision: Tae-Won Park, Myung Ho Lim. Validation: all authors. Writing_original draft: Kyoung Min Kim, Eunju Bae. Writing—review \& editing: all authors. 


\section{ORCID iDs}

Kyoung Min Kim https://orcid.org/0000-0003-0577-0701

Eunju Bae https://orcid.org/0000-0002-8851-9063

Jiryun Lee https://orcid.org/0000-0002-9170-9140

Tae-Won Park https://orcid.org/0000-0001-5980-0756

Myung Ho Lim https://orcid.org/0000-0001-5370-4376

\section{REFERENCES}

1) American Psychiatric Association. Diagnostic and statistical manual of mental disorders: DSM-5. 5th ed. Arlington, VA: American Psychiatric Association;2013.

2) Leckman JF, Bloch MH, Scahill L, King RA. Tourette syndrome: the self under siege. J Child Neurol 2006;21:642-649.

3) McGuire JF, Nyirabahizi E, Kircanski K, Piacentini J, Peterson AL, Woods DW, et al. A cluster analysis of tic symptoms in children and adults with Tourette syndrome: clinical correlates and treatment outcome. Psychiatry Res 2013;210:1198-1204.

4) Pringsheim T, Holler-Managan Y, Okun MS, Jankovic J, Piacentini J, Cavanna AE, et al. Comprehensive systematic review summary: treatment of tics in people with Tourette syndrome and chronic tic disorders. Neurology 2019;92:907-915.

5) Cohen SC, Leckman JF, Bloch MH. Clinical assessment of Tourette syndrome and tic disorders. Neurosci Biobehav Rev 2013;37:9971007.

6) Jankovic J. Tourette syndrome. Phenomenology and classification of tics. Neurol Clin 1997;15:267-275.

7) Knight T, Steeves T, Day L, Lowerison M, Jette N, Pringsheim T. Prevalence of tic disorders: a systematic review and meta-analysis. Pediatr Neurol 2012;47:77-90.

8) Conelea CA, Woods DW. The influence of contextual factors on tic expression in Tourette's syndrome: a review. J Psychosom Res 2008;65:487-496.

9) Rampello L, Alvano A, Battaglia G, Bruno V, Raffaele R, Nicoletti F. Tic disorders: from pathophysiology to treatment. J Neurol 2006; 253:1-15.

10) Ganos C. Tics and Tourette's: update on pathophysiology and tic control. Curr Opin Neurol 2016;29:513-518.

11) Hassan N, Cavanna AE. The prognosis of Tourette syndrome: implications for clinical practice. Funct Neurol 2012;27:23-27.

12) Roessner V, Plessen KJ, Rothenberger A, Ludolph AG, Rizzo R, Skov L, et al. European clinical guidelines for Tourette syndrome and other tic disorders. Part II: pharmacological treatment. Eur Child Adolesc Psychiatry 2011;20:173-196.

13) Müller-Vahl KR, Cath DC, Cavanna AE, Dehning S, Porta M, Robertson MM, et al. European clinical guidelines for Tourette syndrome and other tic disorders. Part IV: deep brain stimulation. Eur Child Adolesc Psychiatry 2011;20:209-217.

14) Roessner V, Schoenefeld K, Buse J, Bender S, Ehrlich S, Münchau A. Pharmacological treatment of tic disorders and Tourette syndrome. Neuropharmacology 2013;68:143-149.

15) Wilhelm S, Peterson AL, Piacentini J, Woods DW, Deckersbach T, Sukhodolsky DG, et al. Randomized trial of behavior therapy for adults with Tourette syndrome. Arch Gen Psychiatry 2012;69:795803.

16) Verdellen C, Van De Griendt J, Hartmann A, Murphy T; ESSTS Guidelines Group. European clinical guidelines for Tourette syndrome and other tic disorders. Part III: behavioural and psychosocial interventions. Eur Child Adolesc Psychiatry 2011;20:197-207.

17) Cath DC, Hedderly T, Ludolph AG, Stern JS, Murphy T, Hartmann A, et al. European clinical guidelines for Tourette syndrome and other tic disorders. Part I: assessment. Eur Child Adolesc Psychiatry 2011;20:155-171.

18) Steeves T, McKinlay BD, Gorman D, Billinghurst L, Day L, Car- roll A, et al. Canadian guidelines for the evidence-based treatment of tic disorders: behavioural therapy, deep brain stimulation, and transcranial magnetic stimulation. Can J Psychiatry 2012;57:144151.

19) Pringsheim T, Doja A, Gorman D, McKinlay D, Day L, Billinghurst L, et al. Canadian guidelines for the evidence-based treatment of tic disorders: pharmacotherapy. Can J Psychiatry 2012;57:133-143.

20) Lim MH, Lee YL, Kim BN. Non-psychopharmacologic therapy of tic or Tourette's disorder. J Korean Acad Child Adolesc Psychiatry 2014;25:53-64.

21) Song JR, Hong JW, Doh JA, Kim HW, Lim MH. Cognitive behavioral therapy in childhood tic disorder: a case of report. J Korean Acad Child Adolesc Psychiatry 2011;22:38-43.

22) Azrin NH, Nunn RG. Habit-reversal: a method of eliminating nervous habits and tics. Behav Res Ther 1973;11:619-628.

23) Turpin G. The behavioural management of tic disorders: a critical review. Adv Behav Res Ther 1983;5:203-245.

24) Fründt $\mathbf{O}$, Woods D, Ganos C. Behavioral therapy for Tourette syndrome and chronic tic disorders. Neurol Clin Pract 2017;7:148156.

25) Leckman JF, Riddle MA, Hardin MT, Ort SI, Swartz KL, Stevenson J, et al. The Yale Global Tic Severity Scale: initial testing of a clinician-rated scale of tic severity. J Am Acad Child Adolesc Psychiatry 1989;28:566-573.

26) Busner J, Targum SD. The clinical global impressions scale: applying a research tool in clinical practice. Psychiatry (Edgmont) 2007;4:28-37.

27) Guy W. ECDEU assessment manual for psychopharmacology. Rockville, MD: National Institute of Mental Health;1976.

28) Shapiro AK, Shapiro E. Controlled study of pimozide vs. placebo in Tourette's syndrome. J Am Acad Child Psychiatry 1984;23:161173.

29) Shytle RD, Silver AA, Sheehan KH, Wilkinson BJ, Newman M, Sanberg PR, et al. The Tourette's Disorder Scale (TODS): development, reliability, and validity. Assessment 2003;10:273-287.

30) Walkup JT, Rosenberg LA, Brown J, Singer HS. The validity of instruments measuring tic severity in Tourette's syndrome. J Am Acad Child Adolesc Psychiatry 1992;31:472-477.

31) Jagger J, Prusoff BA, Cohen DJ, Kidd KK, Carbonari CM, John K. The epidemiology of Tourette's syndrome: a pilot study. Schizophr Bull 1982;8:267-278.

32) Storch EA, Lack CW, Simons LE, Goodman WK, Murphy TK, Geffken GR. A measure of functional impairment in youth with Tourette's syndrome. J Pediatr Psychol 2007;32:950-959.

33) Himle MB, Chang S, Woods DW, Pearlman A, Buzzella B, Bunaciu $L$, et al. Establishing the feasibility of direct observation in the assessment of tics in children with chronic tic disorders. J Appl Behav Anal 2006;39:429-440.

34) Woods DW, Himle MB, Conelea CA. Behavior therapy: other interventions for tic disorders. In: Walkup JT, Mink JW, Hollenbeck PJ, editors. Tourette syndrome. Philadelphia, PA: Lippincott Williams \& Wilkins;2006.

35) Storms L. Massed negative practice as a behavioral treatment for Gilles de la Tourette's syndrome. Am J Psychother 1985;39:277281.

36) Azrin NH, Nunn RG Frantz SE. Habit reversal vs negative practice treatment of nervous tics. Behav Ther 1980;11:169-178.

37) McGuire JF, Ricketts EJ, Piacentini J, Murphy TK, Storch EA, Lewin AB. Behavior therapy for tic disorders: an evidenced-based review and new directions for treatment research. Curr Dev Disord Rep 2015;2:309-317.

38) Deckersbach T, Rauch S, Buhlmann U, Wilhelm S. Habit reversal versus supportive psychotherapy in Tourette's disorder: a randomized controlled trial and predictors of treatment response. Behav Res Ther 2006;44:1079-1090. 
39) Wilhelm S, Deckersbach T, Coffey BJ, Bohne A, Peterson AL, Baer L. Habit reversal versus supportive psychotherapy for Tourette's disorder: a randomized controlled trial. Am J Psychiatry 2003;160:1175-1177.

40) Piacentini J, Woods DW, Scahill L, Wilhelm S, Peterson AL, Chang S, et al. Behavior therapy for children with Tourette disorder: a randomized controlled trial. JAMA 2010;303:1929-1937.

41) O'Connor KP, Brault M, Robillard S, Loiselle J, Borgeat F, Stip E. Evaluation of a cognitive-behavioural program for the management of chronic tic and habit disorders. Behav Res Ther 2001;39: 667-681.

42) Deckersbach T, Chou T, Britton JC, Carlson LE, Reese HE, Siev J, et al. Neural correlates of behavior therapy for Tourette's disorder. Psychiatry Res 2014;224:269-274.

43) Bennett SM, Capriotti M, Bauer C, Chang S, Keller AE, Walkup J, et al. Development and open trial of a psychosocial intervention for young children with chronic tics: the CBIT-JR Study. Behav Ther 2020;51:659-669.

44) Rowe J, Yuen HK, Dure LS. Comprehensive behavioral intervention to improve occupational performance in children with Tourette disorder. Am J Occup Ther 2013;67:194-200.

45) Blount TH, Raj JJ, Peterson AL. Intensive outpatient comprehensive behavioral intervention for tics: a clinical replication series. Cogn Behav Pract 2018;25:156-167.

46) Himle MB, Freitag M, Walther M, Franklin SA, Ely L, Woods DW. A randomized pilot trial comparing videoconference versus face-to-face delivery of behavior therapy for childhood tic disorders. Behav Res Ther 2012;50:565-570.

47) McGuire JF, Piacentini J, Brennan EA, Lewin AB, Murphy TK, Small BJ, et al. A meta-analysis of behavior therapy for Tourette syndrome. J Psychiatr Res 2014;50:106-112.

48) Bate KS, Malouff JM, Thorsteinsson ET, Bhullar N. The efficacy of habit reversal therapy for tics, habit disorders, and stuttering: a meta-analytic review. Clin Psychol Rev 2011;31:865-871.

49) Wile DJ, Pringsheim TM. Behavior therapy for Tourette syndrome: a systematic review and meta-analysis. Curr Treat Options Neurol 2013;15:385-395.

50) Robertson MM, Chowdhury U. Behavioral and psychological therapies for Tourette syndrome and tic disorders: their place in treatment and history. Neuropsychiatry 2011;1:385-400.

51) Dutta N, Cavanna AE. The effectiveness of habit reversal therapy in the treatment of Tourette syndrome and other chronic tic disorders: a systematic review. Funct Neurol 2013;28:7-12.

52) Scahill L, Woods DW, Himle MB, Peterson AL, Wilhelm S, Piacentini JC, et al. Current controversies on the role of behavior therapy in Tourette syndrome. Mov Disord 2013;28:1179-1183.

53) Frank M, Cavanna AE. Behavioural treatments for Tourette syndrome: an evidence-based review. Behav Neurol 2013;27:105-117.

54) Meyer V. Modification of expectations in cases with obsessional rituals. Behav Res Ther 1966;4:273-280.

55) Hoogduin K, Verdellen C, Cath D. Exposure and response prevention in the treatment of Gilles de la Tourette's syndrome: four case studies. Clin Psychol Psychother 1997;4:125-135.

56) Verdellen CW, Keijsers GP, Cath DC, Hoogduin CA. Exposure with response prevention versus habit reversal in Tourettes's syndrome: a controlled study. Behav Res Ther 2004;42:501-511.

57) Bullen JG, Hemsley DR. Sensory experience as a trigger in Gilles de la Tourette's syndrome. J Behav Ther Exp Psychiatry 1983;14: 197-201.

58) Wetterneck CT, Woods DW. An evaluation of the effectiveness of exposure and response prevention on repetitive behaviors associated with Tourette's syndrome. J Appl Behav Anal 2006;39:441-444.

59) Nissen JB, Kaergaard M, Laursen L, Parner E, Thomsen PH. Combined habit reversal training and exposure response prevention in a group setting compared to individual training: a randomized con- trolled clinical trial. Eur Child Adolesc Psychiatry 2019;28:57-68.

60) Cook CR, Blacher J. Evidence-based psychosocial treatments for tic disorders. Clin Psychol 2007;14:252-267.

61) van de Griendt JM, Verdellen CW, van Dijk MK, Verbraak MJ. Behavioural treatment of tics: habit reversal and exposure with response prevention. Neurosci Biobehav Rev 2013;37:1172-1177.

62) Leclerc JB, O'Connor KP, J-Nolin G, Valois P, Lavoie ME. The effect of a new therapy for children with tics targeting underlying cognitive, behavioral, and physiological processes. Front Psychiatry 2016;7:135.

63) O'Connor KP. Cognitive-behavioral management of tic disorders. Hoboken, NJ: John Wiley \& Sons, Ltd.;2005.

64) O'Connor K, St-Pierre-Delorme MÈ, Leclerc J, Lavoie M, Blais MT. Meta-cognitions in Tourette syndrome, tic disorders, and body-focused repetitive disorder. Can J Psychiatry 2014;59:417-425.

65) O’Connor K, Lavoie M, Blanchet P, St-Pierre-Delorme MÊ. Evaluation of a cognitive psychophysiological model for management of tic disorders: an open trial. Br J Psychiatry 2016;209:76-83.

66) O'Connor KP, Lavoie ME, Schoendorff B. Managing tic and habit disorders: a cognitive psychophysiological treatment approach with acceptance strategies. Hoboken, NJ: John Wiley \& Sons, Ltd.;2017.

67) Peterson AL, Azrin NH. An evaluation of behavioral treatments for Tourette syndrome. Behav Res Ther 1992;30:167-174.

68) Reese HE, Vallejo Z, Rasmussen J, Crowe K, Rosenfield E, Wilhelm S. Mindfulness-based stress reduction for Tourette syndrome and chronic tic disorder: a pilot study. J Psychosom Res 2015;78: 293-298.

69) Evers RA, van de Wetering BJ. A treatment model for motor tics based on a specific tension-reduction technique. J Behav Ther Exp Psychiatry 1994;25:255-260.

70) Lavoie ME, Imbriglio TV, Stip E, O'Connor KP. Neurocognitive changes following cognitive-behavioral treatment in Tourette syndrome and chronic tic disorder. Int J Cogn Ther 2011;4:34-50.

71) Meidinger AL, Miltenberger RG, Himle M, Omvig M, Trainor C, Crosby R. An investigation of tic suppression and the rebound effect in Tourette's disorder. Behav Modif 2005;29:716-745.

72) Verdellen CW, Hoogduin CA, Keijsers GP. Tic suppression in the treatment of Tourette's syndrome with exposure therapy: the rebound phenomenon reconsidered. Mov Disord 2007;22:1601-1606.

73) Verdellen CW, Hoogduin CA, Kato BS, Keijsers GP, Cath DC, Hoijtink HB. Habituation of premonitory sensations during exposure and response prevention treatment in Tourette's syndrome. Behav Modif 2008;32:215-227.

74) Houghton DC, Capriotti MR, Scahill LD, Wilhelm S, Peterson AL, Walkup JT, et al. Investigating habituation to premonitory urges in behavior therapy for tic disorders. Behav Ther 2017;48:834-846.

75) Nam SH, Park J, Park TW. Clinical aspects of premonitory urges in patients with Tourette's disorder. J Korean Acad Child Adolesc Psychiatry 2019;30:50-56.

76) O'connor KP, Lavoie ME, Stip E, Borgeat F, Laverdure A. Cognitive-behaviour therapy and skilled motor performance in adults with chronic tic disorder. Neuropsychol Rehabil 2008;18:45-64.

77) Morand-Beaulieu S, O'Connor KP, Blanchet PJ, Lavoie ME. Electrophysiological predictors of cognitive-behavioral therapy outcome in tic disorders. J Psychiatr Res 2018;105:113-122.

78) O'Connor KP, Laverdure A, Taillon A, Stip E, Borgeat F, Lavoie M. Cognitive behavioral management of Tourette's syndrome and chronic tic disorder in medicated and unmedicated samples. Behav Res Ther 2009;47:1090-1095.

79) Sukhodolsky DG, Woods DW, Piacentini J, Wilhelm S, Peterson AL, Katsovich L, et al. Moderators and predictors of response to behavior therapy for tics in Tourette syndrome. Neurology 2017; 88:1029-1036.

80) Specht MW, Nicotra CM, Kelly LM, Woods DW, Ricketts EJ, Perry-Parrish $\mathrm{C}$, et al. A comparison of urge intensity and the proba- 
bility of tic completion during tic freely and tic suppression conditions. Behav Modif 2014;38:297-318.

81) Leckman JF, Zhang H, Vitale A, Lahnin F, Lynch K, Bondi C, et al. Course of tic severity in Tourette syndrome: the first two decades. Pediatrics 1998;102:14-19.

82) Albin RL, Mink JW. Recent advances in Tourette syndrome research. Trends Neurosci 2006;29:175-182.

83) Swain JE, Scahill L, Lombroso PJ, King RA, Leckman JF. Tourette syndrome and tic disorders: a decade of progress. J Am Acad Child Adolesc Psychiatry 2007;46:947-968.

84) Bloch MH, Leckman JF. Clinical course of Tourette syndrome. J Psychosom Res 2009;67:497-501.

85) Murphy TK, Lewin AB, Storch EA, Stock S; American Academy of Child and Adolescent Psychiatry (AACAP) Committee on Quality Issues (CQI). Practice parameter for the assessment and treatment of children and adolescents with tic disorders. J Am Acad Child Adolesc Psychiatry 2013;52:1341-1359.

86) Kim S, Kim E. The use of virtual reality in psychiatry: a review. J Korean Acad Child Adolesc Psychiatry 2020;31:26-32.

87) Schultheis MT, Rizzo AA. The application of virtual reality technology in rehabilitation. Rehabil Psychol 2001;46:296-311.

88) Maples-Keller JL, Bunnell BE, Kim SJ, Rothbaum BO. The use of virtual reality technology in the treatment of anxiety and other psychiatric disorders. Harv Rev Psychiatry 2017;25:103-113.

89) Oing T, Prescott J. Implementations of virtual reality for anxietyrelated disorders: systematic review. JMIR serious games 2018;6: e10965.

90) McGuire JF, Ginder N, Ramsey K, Essoe JK, Ricketts EJ, McCracken JT, et al. Optimizing behavior therapy for youth with Tourette's disorder. Neuropsychopharmacology 2020;45:2114-2119. 